\title{
Purinergic Signaling: A Common Path in the Macrophage Response against Mycobacterium tuberculosis and Toxoplasma gondii
}

\author{
Laetitia Petit-Jentreau $^{1 *}$, Ludovic Tailleux ${ }^{2,3}$ and Janine L. Coombes ${ }^{1}$ \\ ${ }^{1}$ Institute of Infection and Global Health, Department of Infection Biology, University of Liverpool, Liverpool, United Kingdom, \\ ${ }^{2}$ Mycobacterial Genetics Unit, Institut Pasteur, Paris, France, ${ }^{3}$ Unit for Integrated Mycobacterial Pathogenomics, Institut \\ Pasteur, Paris, France
}

OPEN ACCESS

Edited by:

Özlem Yilmaz,

Medical University of South Carolina,

United States

Reviewed by:

Ana Carolina Morandini,

Arthur A. Dugoni School of Dentistry, University of the Pacific, United States

Robson Coutinho-Silva,

Federal University of Rio de Janeiro,

Brazil

Ali Abdul Sater,

York University, Canada

*Correspondence:

Laetitia Petit-Jentreau

jentreau@liverpool.ac.uk;

laetitia.petit.jentreau@gmail.com

Received: 19 June 2017

Accepted: 21 July 2017

Published: 07 August 2017

Citation:

Petit-Jentreau L, Tailleux L and Coombes JL (2017) Purinergic

Signaling: A Common Path in the Macrophage Response against Mycobacterium tuberculosis and

Toxoplasma gondii.

Front. Cell. Infect. Microbiol. 7:347.

doi: 10.3389/fcimb.2017.00347
Immune responses are essential for the protection of the host against external dangers or infections and are normally efficient in the clearance of invading microbes. However, some intracellular pathogens have developed strategies to replicate and survive within host cells resulting in latent infection associated with strong inflammation. This excessive response can cause cell and tissue damage and lead to the release of the intracellular content, in particular the nucleotide pool, into the extracellular space. Over the last decade, new studies have implicated metabolites from the purinergic pathway in shaping the host immune response against intracellular pathogens and proved their importance in the outcome of the infection. This review aims to summarize how the immune system employs the purinergic system either to fight the pathogen, or to control collateral tissue damage. This will be achieved by focusing on the macrophage response against two intracellular pathogens, the human etiologic agent of tuberculosis, Mycobacterium tuberculosis and the protozoan parasite, Toxoplasma gondii.

Keywords: purinergic agents, Mycobacterium tuberculosis, Toxoplasma gondii, ATP, macrophages, innate immunity, nucleotides

\section{INTRODUCTION}

Purinergic nucleotides are largely known for their role as the primary energy currency of cells. However, it has been demonstrated that these nucleotides are also implicated in the modulation of the immune response (Burnstock and Boeynaems, 2014; Cekic and Linden, 2016). During inflammation, infection or after tissue injury, purines can be released into the extracellular space either passively by dying or damaged cells, or actively via pannexin or connexin hemichannels from immune cells (Beyer and Steinberg, 1991; Bao et al., 2004; Pelegrin and Surprenant, 2009; Figure 1). Extracellular ATP (eATP) is the most studied purine for its capacity to modulate the immune response. Once in the extracellular environment, eATP is rapidly metabolized to adenosine diphosphate (eADP) and adenosine monophosphate (eAMP) by alkaline phosphatases, ectonucleotide pyrophosphatases/phosphodiesterases (ENPPs) or ecto-nucleoside triphosphate diphosphohydrolases (ENTPDases) which includes the ectonucleoside triphosphate diphosphorylase 1, CD39 (Burnstock and Boeynaems, 2014). eAMP is then converted to adenosine by the ecto-5'-nucleotidase, CD73 (Burnstock and Boeynaems, 2014). Extracellular adenosine (eADO) is finally metabolized into extracellular inosine by the adenosine deaminase (ADA). In order to modulate the immune response, purine metabolites act through two families of purinergic 


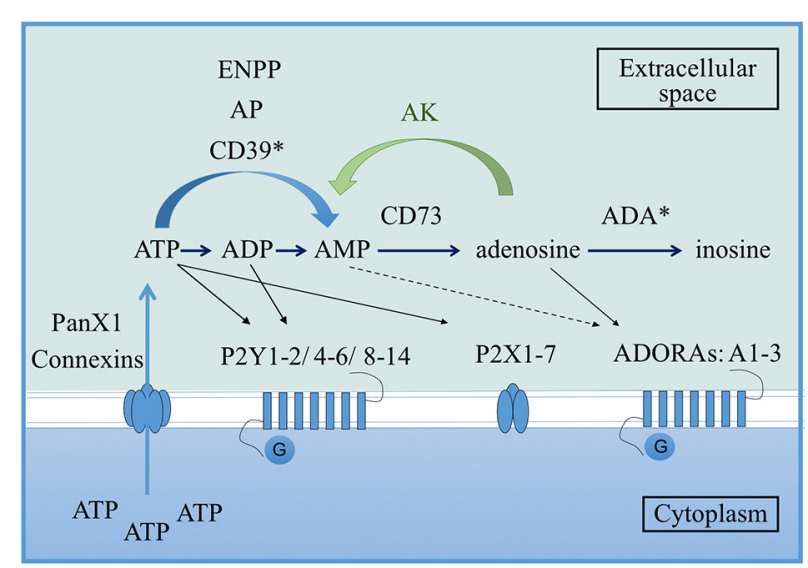

FIGURE 1 | Overview of the purinergic pathway. From the cytoplasm to the extracellular space, ATP can be released via pannexin 1 (PanX1) or connexin hemichannels present on the cell membrane. Once in the extracellular environment, ATP is rapidly converted to ADP and AMP by alkaline phosphatases (AP), ectonucleotide pyrophosphatases/phosphodiesterases (ENPPS) or ecto-nucleoside triphosphate diphosphohydrolases which includes the ectonucleoside triphosphate diphosphorylase 1 (CD39). AMP is then converted to adenosine via the ecto- $5^{\prime}$-nucleotidase CD73. Finally, adenosine is metabolized into inosine by the adenosine deaminase (ADA). Adenosine can be reversely converted into AMP by adenosine kinase (AK). In terms of receptors, ATP binds $\mathrm{P} 2$ receptors (either the membrane ion-channels $\mathrm{P} 2 \mathrm{X}$ or the $G$ protein-coupled receptors P2Y), ADP preferentially binds the P2Y receptors and adenosine binds the $\mathrm{G}$ protein-coupled receptors $\mathrm{P} 1$ also known as ADORAs. Asterisks correspond to enzymes that can be extracellular or at the surface of the cell membrane (Velasquez and Eugenin, 2014). purinergic pathway. Both pathogens cause major public health problems worldwide: $M$. tuberculosis is the human etiologic agent of tuberculosis (TB), while the apicomplexan parasite, T. gondii causes serious health problems in immunocompromised people and the developing fetus. These pathogens infect, respectively, one-third of the human population and have co-evolved with the human population for centuries (McLeod et al., 2009). Both infections share many characteristics, they can cause acute disease, or they can be latent and asymptomatic. Latent infections represent the majority of the cases after infection with either of these two pathogens. Latency could be explained by the capacity of both pathogens to survive and replicate in cells of the monocyte/macrophage lineage, and their capacity to shield them from the immune response by residing in a non-fusogenic vacuole inside the macrophage. However, in immunocompromised people, both infections manifest as acute disease. Induced pathologies are characterized by a pro-inflammatory Th1 response with a dysregulated immune response leading to a strong inflammation and collateral associated tissue damage.

During these infections, modulators are need to alert, stimulate, and regulate the immune system and nucleotides from the purinergic pathway could be one of them. In this context, these two intracellular pathogens are really good models to study the role of these purinergic mediators in the control of intracellular infections during acute phase of the disease. Here, we will discuss the recent advances in the purinergic pathway field by comparing the macrophage response against M. tuberculosis and T. gondii.

\section{eATP AND P2X7 RECEPTOR: THE KILLER SIDE OF THE FORCE}

to $\mathrm{P} 2$ receptors which are divided into ionotropic P2X and metabotropic P2Y subtypes (Ralevic and Burnstock, 1998). P1 receptors, which are also known as ADORAs receptors or $\mathrm{A} 1$, $\mathrm{A} 2 \mathrm{~A}, \mathrm{~A} 2 \mathrm{~B}, \mathrm{~A} 3$, preferentially recognize eADO (Burnstock and Boeynaems, 2014; Figure 1).

In the extracellular environment, ATP is recognized as a Damage Associated Molecular Pattern (DAMP). High concentrations of eATP alert the immune system and mediate pro-inflammatory effects. eATP induces granule release by neutrophils, T-cell activation, cytokine and chemokine secretion by macrophages, generation of reactive oxygen (ROS) or nitrogen species and dendritic cell maturation and migration (Bours et al., 2006). By contrast, eADO is best known for its immunosuppressive capacities, inhibiting neutrophil phagocytosis via the activation of $\mathrm{A} 2 \mathrm{~A}$ receptor and ROS generation by macrophages and neutrophils, improving the secretion by macrophages of wound healing and angiogenesis molecules such as, VEGF and inducing a Th2-like profile (Bours et al., 2006).

Here, we will discuss how members of this pathway can be employed by macrophages to combat intracellular pathogens or to dampen inflammation. By focusing on the response against two different pathogens: Mycobacterium tuberculosis (M. tuberculosis) and Toxoplasma gondii (T. gondii), we will demonstrate the highly conserved mechanisms used by the
Cells from the macrophage/monocyte lineage represent one of first lines of defense against infection, and are the main cell targets for invasion by $M$. tuberculosis or T. gondii. Due to their important contribution to pathogen clearance, a number of studies have been focused on the role played by the purinergic pathway in influencing macrophage killing function. In 1994, Molloy et al. provided the first evidence for the capacity of $1 \mathrm{mM}$ eATP to induce mycobacterial killing by human monocytes (Molloy et al., 1994). Lammas et al. corroborated these observations and proved that the activation of the eATP specific P2X7 receptor (P2X7R) with $3 \mathrm{mM}$ ATP for $30 \mathrm{~min}$ was necessary to induce apoptosis of BCG-infected macrophages and killing of the bacteria, both independently of ROI/RNI (Lammas et al., 1997). Further studies demonstrated that this mycobacterial killing mechanism was dependent either on phospholipase D activation (Kusner and Adams, 2000; Fairbairn et al., 2001) or followed the apoptosis of infected macrophages (Placido et al., 2006). Similarly, using a T. gondii infection model, Correa et al. demonstrated that stimulation of murine macrophages with $3 \mathrm{mM}$ ATP for $30 \mathrm{~min}$ triggered the elimination of the parasite in a P2X7R dependent manner (Corrêa et al., 2010). This killing was associated with an increase in production of ROS in infected macrophages after ATP stimulation. Lees et al. confirmed these 
murine data and provided evidence that P2X7R mediated killing of $T$. gondii is independent of nitric oxide (NO) secretion but is associated with host cell apoptosis (Lees et al., 2010). Overall, these data suggest a conserve mechanism for ATP in the control of bacterial or parasitic infection. High concentrations of ATP activate the P2X7R and can induce the apoptosis of infected cells leading to the death of the pathogen (Figure 2).

The role of P2X7R in the control of infection is also suggested by studies focusing on P2X7R polymorphisms in the human population. The P2X7R gene is highly polymorphic and different non-synonymous single nucleotide polymorphisms (SNPs) have been described (Sluyter and Stokes, 2011). The 1513A $>$ C polymorphism, conferring a loss of function of the receptor, has been extensively studied in control of intracellular pathogen infections. Lees et al. (2010) demonstrated that macrophages from a patient with the $1513 \mathrm{~A}>\mathrm{C}$ polymorphism would be less effective at killing $T$. gondii tachyzoites after ATP exposure than macrophages from people with the 1513A wild-type (WT) allele. Another study provided evidence for an association between loss of function of P2X7R caused by another SNP, $1068 \mathrm{~T}>\mathrm{C}$, and retinal toxoplasmosis (Jamieson et al., 2010). These publications demonstrated an important role of the P2X7R in the determination of resistance or susceptibility to acquired T. gondii infection (Jamieson et al., 2010). The association of P2X7R gene polymorphisms with resistance to TB in humans was also studied in different meta-analyses where the $1513 \mathrm{~A}>\mathrm{C}$ loss of function SNP was associated with susceptibility to pulmonary (Sharma et al., 2010; Areeshi et al., 2013; Wu et al., 2015; Shamsi et al., 2016) and extra-pulmonary TB (Sharma et al., 2010; BenSelma et al., 2011; Singla et al., 2012). This susceptibility was due to the reduction of the capacity of macrophages to kill the bacillus (Fernando et al., 2007). Moreover, TB patients carrying this $1513 \mathrm{~A}>\mathrm{C}$ allele presented an increase number of bacilli in sputum than people with the WT allele, strongly implicating this particular SNP in the modulation of mycobacterial immunity (Wu et al., 2015). Others alleles for the P2X7R gene, such as, P2X7R-762C and P2X7R-1229T were also associated with a high risk of developing TB in the worldwide population (Sambasivan et al., 2010; Singla et al., 2012; Wu et al., 2015). At a global level, it has been described that the expression of P2X7R mRNA was higher in the PBMCs from TB patients compared to control patients (Franco-Martínez et al., 2006).

The role of $\mathrm{P} 2 \mathrm{X} 7 \mathrm{R}$ in human diseases was clearly demonstrated but its implications in mouse models of infection are less well characterized. In an oral model of toxoplasmic ileitis with 10 cysts of ME49 strain, Miller et al. showed no differences in parasite loads between P2X7R knock-out (KO) mice and WT mice but animals deficient for the receptor exhibit higher degrees of intestinal pathology associated with elevated ileal concentrations of pro-inflammatory cytokines (Miller et al., 2015). By contrast, Huang et al. demonstrated the high susceptibility to $\mathrm{P} 2 \mathrm{X} 7 \mathrm{R} \mathrm{KO}$ mice to $T$. gondii infection in an oral infection with high numbers of tachyzoites from $\mathrm{RH}$ or Prugniaud strain (Huang et al., 2016). This study showed a higher T. gondii tachyzoite burden in the ileum of orally-infected P2X7R KO mice 5 days post-infection compared to the WT

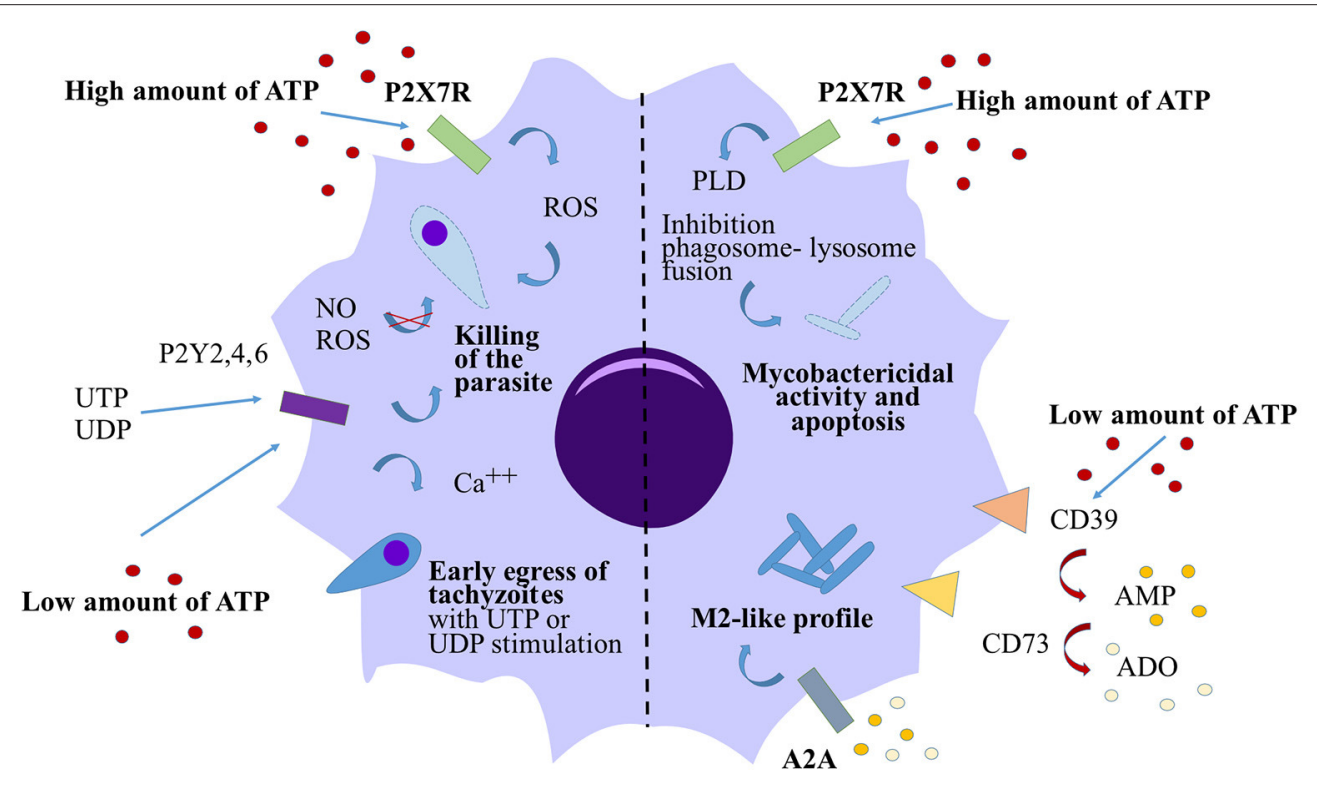

FIGURE 2 | Action of eATP on macrophage response against T. gondii and M. tuberculosis. High concentrations of eATP (3-5 mM) induce the activation of P2X7R on either T. gondii- or M. tuberculois- infected macrophages and induce the killing of the pathogen in both cases. The killing of the parasite is dependent on ROS generation however the mycobactericidal activity is due to the activation of the phophalipase D (PLD). In both cases, high levels of eATP induce macrophage apoptosis. By contrast, low levels of eATP $(100 \mu \mathrm{M})$ are rapidly converted to eAMP and eADO via CD39 and CD73. eAMP and eADO bind the adenosine receptor A2A leading to a switch in macrophage polarization toward a M2-like profile in M. tuberculosis-infected macrophages. Low levels of ATP control T. gondii infection via pyrimidinergic receptor activation without affecting the macrophage death or the production of NO or ROS. UTP or UDP stimulations induce premature egress of tachyzoites through $\mathrm{P} 2 \mathrm{Y}$ receptors. 
mice. This elevated parasite burden was accompanied by an impaired recruitment of $\mathrm{CD}_{103}{ }^{+}$dendritic cells to the small intestine in the knockout infected animals compared to WT mice due to the reduced chemokine production by P2X7R KO epithelial cells (Huang et al., 2016). The high susceptibility of P2X7R KO mice to T. gondii compared to their WT counterpart were also confirmed in a model of acute toxoplasmosis. P2X7R KO mice succumbed faster to the infection, lost more weight, had higher parasitic loads and produced less pro-inflammatory cytokines than WT mice after intra peritoneal infections with two different strains RH or ME49 (Miller et al., 2011; Corrêa et al., 2016).

In the TB infection mouse model, the susceptibility of the P2X7R deficient mice to the infection is critically dependent on the mycobacterial dose and strains used. An initial study indicated that P2X7R was not involved in the control of pulmonary TB in mice infected with a low dose of $M$. tuberculosis Erdman strain using the aerosol route (Myers et al., 2005). By contrast, a study demonstrated that mice lacking P2X7R had a higher mycobacterial burden in the lungs compared to WT animals infected intravenously with a high dose of the common laboratory strain H37Rv (Santos et al., 2013). However, two recent papers suggested a role for the P2X7R in Bone Marrowderived cells in aggressive forms of tuberculosis only (Amaral et al., 2014; Bomfim et al., 2017). In these studies, mice deficient for the P2X7R infected with virulent strains (Beijing1471 or MP287/03), but not with $\mathrm{H} 37 \mathrm{Rv}$ strain, were less susceptible than WT mice (Amaral et al., 2014). Infected P2X7R KO mice or chimeric mice adoptively transferred with P2X7R KO bone marrow cells presented a decrease in the bacterial load and in the gross pathology in the lungs compared to their counterparts (Amaral et al., 2014; Bomfim et al., 2017). Moreover, the authors showed that hypervirulent mycobacteria induce macrophage necrosis in a P2X7R-dependent mechanism (Amaral et al., 2014). This deleterious role of $P 2 X 7 R$ in severe $T B$ can be explained by a vicious cycle where high concentrations of eATP is released by necrotic cells and lead to lung damage and bacillus dissemination.

\section{AATP: A ROLE OUTSIDE PATHOGEN KILLING?}

Dependently of the concentration, eATP may also play opposite roles in the outcome of the infection. Activation of the P2X7R with very high concentrations of ATP (3-5 mM) were clearly necessary to decrease the bacterial load or parasitic burden in vitro and these concentrations of ATP are determinant in tissue pathology in vivo. However, these high concentrations of ATP were shown to induce the apoptosis of either $T$. gondii-infected murine macrophages or M. tuberculosis-infected macrophages (Lees et al., 2010; Figure 2). Canaday et al. (2002) demonstrated that human monocytes exposed to 1-3 mM ATP were directly lysed after $4 \mathrm{~h}$ of stimulation whereas $300 \mu \mathrm{M}$ ATP didn't cause any cell death. In the same study, they suggested that $\mathrm{T}$ cells or bystander myeloid cells release very low concentrations of ATP after degranulation and they proved that this bystander eATP was not sufficient to kill intracellular BCG by monocytes. However, in T. gondii-infected murine macrophages, $100 \mu \mathrm{M}$ ATP was sufficient to reduce the parasite burden in a $\mathrm{P} 2 \mathrm{Y}$ receptor dependent manner, without affecting the macrophage death and their capacity to generate NO or ROS production (Moreira-Souza et al., 2015; Figure 2). By contrast, our group recently demonstrated that stimulation with $100 \mu \mathrm{M}$ eATP did not trigger $M$. tuberculosis elimination by human monocyte-derived macrophages (Dubois-Colas et al., 2014). Moreover, stimulation with $100 \mu \mathrm{M}$ ATP induced a switch in the macrophage polarization into an M2 phenotype. M. tuberculosis-infected cells and treated with ATP, secreted less pro-inflammatory cytokines but were able to secrete more cytokines implicated in wound healing. After $18 \mathrm{~h}$ of stimulation with $100 \mu \mathrm{M}$ ATP, eAMP was the main metabolite found by mass spectrometry in the supernatants of $M$. tuberculosisinfected macrophages. In this study, eATP degradation into eAMP or eADO was necessary to induce the M2-like profile both acting through $\mathrm{A} 2 \mathrm{~A}$ receptor activation (Figure 2). In that model, this concentration of ATP associated with its degradation may limit tissue damage but may also favor bacterial immune escape.

\section{THE FORGOTTEN ROLE OF METABOLITES FROM EATP DEGRADATION}

Over last decade, knock-out mouse models for enzymes involved in eATP degradation have been used to determine the role of the different purinergic nucleotides in the immune response against intracellular pathogens. CD39 is the first enzyme involved in ATP degradation, hydrolyzing eATP into eAMP (Figure 1). The role of this ectonucleotidase has been poorly explored in infectious diseases but a population of $\mathrm{CD} 4{ }^{+} \mathrm{CD} 25^{+} \mathrm{CD} 39^{+}$ $\mathrm{T}$ cells with regulatory properties were identified from blood of patients with active TB (Chiacchio et al., 2009). More recently, a study described a functional role for CD39 in the suppressive action of a population of Mycobacterium bovisactivated CD8 T cells (Boer et al., 2013). These data suggested that $\mathrm{CD} 39$ could be a new marker for the human regulatory CD4 or CD8 T cell populations (Miller et al., 2011; Boer et al., 2013).

In contrast to CD39, the role of the ecto- $5^{\prime}$-nucleotidase CD73 in the outcome of intracellular infections in vivo has been better characterized. CD73 is involved in the conversion of eAMP into eADO (Figure 1). CD73 is a glycosylphosphatidylinositol-linked surface protein expressed by the majority of immune cells but is not highly expressed by macrophages (Antonioli et al., 2013; Dubois-Colas et al., 2014). In the context of infection, the majority of studies have been carried out using CD73 KO mice. Mahamed et al. provided the first evidence of a role for CD73 in Toxoplasma gondii infection. After oral infection with T. gondii, mice deficient for CD73 were more resistant to chronic infection, displaying decreased cyst burden in the brain compared to wild-type animals (Mahamed et al., 2012). The same authors described recently, that, contrary to chronic disease, mice deficient in CD73 were highly susceptible to acute 
toxoplasmosis due to damage mediated by the immune system (Mahamed et al., 2015). Thus, CD73 seems to play a role in limiting tissue damage during acute infection with $T$. gondii. This was also supported by the downregulation of CD73 expression in the small intestine during lethal ileitis triggered by oral infection of C57BL/6 mice, leading to an impaired capacity to produce eADO (Francois et al., 2015). By contrast, CD73 was not involved in the protection of M. tuberculosis-infected mice either at early stage of the infection or after 2 months of infection (Petit-Jentreau et al., 2015). Although M. tuberculosisinfected mice lacking the receptor were not more susceptible to TB than their WT counterpart, they presented a higher inflammation in the lungs due to the absence of eADO (PetitJentreau et al., 2015). The lungs of M. tuberculosis-infected CD73 KO showed a higher neutrophil recruitment at early stage of the infection compared to WT mice (Petit-Jentreau et al., 2015). The ectonucleotidase CD73 can also prevent the early recruitment of neutrophils on the site of the infection after T. gondii invasion limiting the inflammation (Mahamed et al., 2015). This common observation was also observed during septic choc (Haskó et al., 2011) and acute lung injury induced by lipopolysaccharide injections (Reutershan et al., 2009) where eADO can dampen the inflammation.

eADO is not the final metabolite of the purinergic pathway: it is then converted into its less functional metabolite eInosine by enzymes including adenosine-deaminase (ADA; Figure 1). During $\mathrm{TB}$, eADA is present at a high concentration in the pleural liquid of infected patients (Dimakou et al., 2009) and measurement of eADA enzymatic activity in the lungs of infected patients could serve as a marker for TB infection (Blake and Berman, 1982). During toxoplasmosis, ADA activity is increased in rat $\mathrm{T}$ cells infected by RH T. gondii compared to non-infected rat (Tonin et al., 2013) but a recent study showed that eADA activity was differently modulated on the brain of $T$. gondii infected mice depending on the strain and the stage of the infection (Tonin et al., 2014). They demonstrated a decrease of eADA activity in the brain after acute infection with $\mathrm{RH}$ strain but an increase of the activity in the brain during the chronic phase of the infection with the cystogenic strain ME-49 supporting the idea that adenosine is necessary to decrease the inflammation.

\section{REFERENCES}

Amaral, E. P., Ribeiro, S. C., Lanes, V. R., Almeida, F. M., de Andrade, M. R., Bomfim, C. C., et al. (2014). Pulmonary infection with hypervirulent Mycobacteria reveals a crucial role for the P2X7 receptor in aggressive forms of tuberculosis. PLoS Pathog. 10:e1004188. doi: 10.1371/journal.ppat.1004188

Antonioli, L., Pacher, P., Vizi, E. S., and Haskó, G. (2013). CD39 and CD73 in immunity and inflammation. Trends Mol. Med. 19, 355-367. doi: 10.1016/j.molmed.2013.03.005

Areeshi, M. Y., Mandal, R. K., Panda, A. K., and Haque, S. (2013). Association of P2X7 A1513C (rs3751143) gene polymorphism with risk of tuberculosis: evidence from a meta-analysis. Genet. Test. Mol. Biomarkers 17, 662-668. doi: $10.1089 /$ gtmb.2013.0202

Bao, L., Locovei, S., and Dahl, G. (2004). Pannexin membrane channels are mechanosensitive conduits for ATP. FEBS Lett. 572, 65-68. doi: 10.1016/j.febslet.2004.07.009

\section{SUMMARY}

From parasitic to mycobacterial infections, this review underlines the very conserved and important role played by the purinergic pathway in the control of intracellular pathogens by the immune system. In this context, the ATP-mediated killing associated with activation of the P2X7R is necessary to avoid the replication of either T. gondii or M. tuberculosis in vitro and loss of function of the P2X7R in the human population by SNP in the P2X7R allele induces an higher susceptibility in the outcome of the two diseases. Adenosine generated via CD73 activity is also necessary to dampen the inflammation in acute models of both infections.

However, the action of the purinergic pathway should not solely be considered as the pro-inflammatory functions of eATP on one side, and the immunosuppressive properties of eADO (Cekic and Linden, 2016) on the other. With the recently described role played by lower concentrations of ATP $(100 \mu \mathrm{M})$ and metabolites from ATP degradation (in particular eAMP) in limiting tissue damage during $M$. tuberculosis infection, new studies are now necessary to better understand the regulation of this balance between pro- and anti-inflammatory effects. In this review, we have discussed the complexity of this pathway where depending on the concentration used, the receptor or the enzyme involved, metabolites from the purinergic pathway can generate opposite effects. Members of the purinergic pathway represent now promising curative strategy for intracellular infections (Soares-Bezerra et al., 2015).

\section{AUTHOR CONTRIBUTIONS}

LP-J wrote the paper with input from LT and JLC. All authors revised the manuscript, and approved it for publication.

\section{ACKNOWLEDGMENTS}

The present work was supported by the University of Liverpool. JLC is a lecturer at the University of Liverpool, UK; LT is a researcher at Institut Pasteur, France; and LP-J is a postdoctoral researcher on the JLC's Biotechnology and Biological Sciences Research Council (BBSRC) grant (BB/M023540/1) at the University of Liverpool, UK.

Ben-Selma, W., Ben-Kahla, I., Boukadida, J., and Harizi, H. (2011). Contribution of the P2X7 1513A/C loss-of-function polymorphism to extrapulmonary tuberculosis susceptibility in Tunisian populations. FEMS Immunol. Med. Microbiol. 63, 65-72. doi: 10.1111/j.1574-695X.2011.0 0824.x

Beyer, E. C., and Steinberg, T. H. (1991). Evidence that the gap junction protein connexin-43 is the ATP-induced pore of mouse macrophages. J. Biol. Chem. 266, 7971-7974.

Blake, J., and Berman, P. (1982). The use of adenosine deaminase assays in the diagnosis of tuberculosis. S. Afr. Med. J. 62, 19-21.

Boer, M. C., van Meijgaarden, K. E., Bastid, J., Ottenhoff, T. H., and Joosten, S. A. (2013). CD39 is involved in mediating suppression by Mycobacterium bovis BCG-activated human $\mathrm{CD}^{+} \mathrm{CD}^{+} 9^{+}$regulatory T cells. Eur. J. Immunol. 43, 1925-1932. doi: 10.1002/eji.201243286

Bomfim, C. C. B., Amaral, E. P., Cassado, A. D. A., Salles, É. M., do Nascimento, R. S., Lasunskaia, E., et al. (2017). P2X7 receptor in bone marrow-derived cells 
aggravates Tuberculosis caused by hypervirulent Mycobacterium bovis. Front. Immunol. 8:435. doi: 10.3389/fimmu.2017.00435

Bours, M. J., Swennen, E. L., Di Virgilio, F., Cronstein, B. N., and Dagnelie, P. C. (2006). Adenosine 5'-triphosphate and adenosine as endogenous signaling molecules in immunity and inflammation. Pharmacol. Ther. 112, 358-404. doi: 10.1016/j.pharmthera.2005.04.013

Burnstock, G. (2017). Introduction to the special issue on purinergic receptors. Adv. Exp. Med. Biol. 64, 445-446. doi: 10.1007/5584_2017_12

Burnstock, G., and Boeynaems, J.-M. (2014). Purinergic signalling and immune cells. Purinergic Signal. 10, 529-564. doi: 10.1007/s11302-014-9427-2

Canaday, D. H., Beigi, R., Silver, R. F., Harding, C. V., Boom, W. H., and Dubyak, G. R. (2002). ATP and control of intracellular growth of mycobacteria by T cells. Infect. Immun. 70, 6456-6459. doi: 10.1128/IAI.70.11.6456-6459.2002

Cekic, C., and Linden, J. (2016). Purinergic regulation of the immune system. Nat. Rev. Immunol. 16, 177-192. doi: 10.1038/nri.2016.4

Chiacchio, T., Casetti, R., Butera, O., Vanini, V., Carrara, S., Girardi, E., et al. (2009). Characterization of regulatory $\mathrm{T}$ cells identified as $\mathrm{CD} 4^{+} \mathrm{CD} 25^{\text {high }} \mathrm{CD} 39^{+}$in patients with active tuberculosis. Clin. Exp. Immunol. 156, 463-470. doi: 10.1111/j.1365-2249.2009.03908.x

Corrêa, G., Almeida Lindenberg, C., Moreira-Souza, A. C., Savio, L. E., Takiya, C. M., Marques-da-Silva, C., et al. (2016). Inflammatory early events associated to the role of P2X7 receptor in acute murine toxoplasmosis. Immunobiology 222, 676-683. doi: 10.1016/j.imbio.2016.12.007

Corrêa, G., Marques-da-Silva, C., de Abreu Moreira-Souza, A. C., Vommaro, R. C., and Coutinho-Silva, R. (2010). Activation of the P2X(7) receptor triggers the elimination of Toxoplasma gondii tachyzoites from infected macrophages. Microbes Infect. 12, 497-504. doi: 10.1016/j.micinf.2010.03.004

Dimakou, K., Hillas, G., and Bakakos, P. (2009). Adenosine deaminase activity and its isoenzymes in the sputum of patients with pulmonary tuberculosis. Int. J. Tuberc. Lung Dis. 13, 744-748.

Dubois-Colas, N., Petit-Jentreau, L., Barreiro, L. B., Durand, S., Soubigou, G., Lecointe, C., et al. (2014). Extracellular adenosine triphosphate affects the response of human macrophages infected with Mycobacterium tuberculosis. J. Infect. Dis. 210, 824-833. doi: 10.1093/infdis/jiu135

Fairbairn, I. P., Stober, C. B., Kumararatne, D. S., and Lammas, D. A. (2001). ATPmediated killing of intracellular mycobacteria by macrophages is a $\mathrm{P} 2 \mathrm{X}(7)$ dependent process inducing bacterial death by phagosome-lysosome fusion. J. Immunol. 167, 3300-3307. doi: 10.4049/jimmunol.167.6.3300

Fernando, S. L., Saunders, B. M., Sluyter, R., Skarratt, K. K., Goldberg, H., Marks, G. B., et al. (2007). A polymorphism in the P2X7 gene increases susceptibility to extrapulmonary tuberculosis. Am. J. Respir. Crit. Care Med. 175, 360-366. doi: 10.1164/rccm.200607-970OC

Francois, V., Shehade, H., Acolty, V., Preyat, N., Delrée, P., Moser, M., et al. (2015). Intestinal immunopathology is associated with decreased CD73generated adenosine during lethal infection. Mucosal Immunol. 8, 773-784. doi: $10.1038 / \mathrm{mi} .2014 .108$

Franco-Martínez, S., Niño-Moreno, P., Bernal-Silva, S., Baranda, L., Rocha-Meza, M., Portales-Cervantes, L., et al. (2006). Expression and function of the purinergic receptor P2X7 in patients with pulmonary tuberculosis. Clin. Exp. Immunol. 146, 253-261. doi: 10.1111/j.1365-2249.2006.03213.X

Haskó, G., Csóka, B., Koscsó, B., Chandra, R., Pacher, P., Thompson, L. F., et al. (2011). Ecto-5' -nucleotidase (CD73) decreases mortality and organ injury in sepsis. J. Immunol. 187, 4256-4267. doi: 10.4049/jimmunol.1003379

Huang, S.-W., Walker, C., Pennock, J., Else, K., Muller, W., Daniels, M. J., et al. (2016). P2X7 receptor-dependent tuning of gut epithelial responses to infection. Immunol. Cell Biol. 95, 178-188. doi: 10.1038/icb.2016.75

Jamieson, S. E., Peixoto-Rangel, A. L., Hargrave, A. C., Roubaix, L. A., Mui, E. J., Boulter, N. R., et al. (2010). Evidence for associations between the purinergic receptor $\mathrm{P} 2 \mathrm{X}(7)$ (P2RX7) and toxoplasmosis. Genes Immun. 11, 374-383. doi: 10.1038/gene.2010.31

Kusner, D. J., and Adams, J. (2000). ATP-induced killing of virulent Mycobacterium tuberculosis within human macrophages requires phospholipase D. J. Immunol. 164, 379-388. doi: 10.4049/jimmunol.164.1.379

Lammas, D. A., Stober, C., Harvey, C. J., Kendrick, N., Panchalingam, S., and Kumararatne, D. S. (1997). ATP-induced killing of mycobacteria by human macrophages is mediated by purinergic $\mathrm{P} 2 \mathrm{Z}(\mathrm{P} 2 \mathrm{X} 7)$ receptors. Immunity 7 , 433-444. doi: 10.1016/S1074-7613(00)80364-7
Lees, M. P., Fuller, S. J., McLeod, R., Boulter, N. R., Miller, C. M., Zakrzewski, A. M., et al. (2010). P2X7 receptor-mediated killing of an intracellular parasite, Toxoplasma gondii, by human and murine macrophages. J. Immunol. 184, 7040-7046. doi: 10.4049/jimmunol.1000012

Mahamed, D. A., Mills, J. H., Egan, C. E., Denkers, E. Y., and Bynoe, M. S. (2012). CD73-generated adenosine facilitates Toxoplasma gondii differentiation to long-lived tissue cysts in the central nervous system. Proc. Natl. Acad. Sci. U.S.A. 109, 16312-16317. doi: 10.1073/pnas.1205589109

Mahamed, D. A., Toussaint, L. E., and Bynoe, M. S. (2015). CD73-generated adenosine is critical for immune regulation during Toxoplasma gondii infection. Infect. Immun. 83, 721-729. doi: 10.1128/IAI.02536-14

McLeod, R., Kieffer, F., Sautter, M., Hosten, T., and Pelloux, H. (2009). Why prevent, diagnose and treat congenital toxoplasmosis? Mem. Inst. Oswaldo Cruz 104, 320-344. doi: 10.1590/S0074-02762009000200029

Miller, C. M., Zakrzewski, A. M., Ikin, R. J., Boulter, N. R., Katrib, M., Lees, M. P., et al. (2011). Dysregulation of the inflammatory response to the parasite, Toxoplasma gondii, in P2X7 receptor-deficient mice. Int. J. Parasitol. 41, 301-308. doi: 10.1016/j.ijpara.2010.10.001

Miller, C. M., Zakrzewski, A. M., Robinson, D. P., Fuller, S. J., Walker, R. A., Ikin, R. J., et al. (2015). Lack of a functioning P2X7 receptor leads to increased susceptibility to Toxoplasmic Ileitis. PLOS ONE 10:e0129048. doi: 10.1371/journal.pone.0129048

Molloy, A., Laochumroonvorapong, P., and Kaplan, G. (1994). Apoptosis, but not necrosis, of infected monocytes is coupled with killing of intracellular bacillus Calmette-Guérin. J. Exp. Med. 180, 1499-1509. doi: 10.1084/jem.180. 4.1499

Moreira-Souza, A. C. A., Marinho, Y., Correa, G., Santoro, G. F., Coutinho, C. M., Vommaro, R. C., et al. (2015). Pyrimidinergic receptor activation controls Toxoplasma gondii infection in macrophages. PLOS ONE 10:e0133502. doi: 10.1371/journal.pone.0133502

Myers, A. J., Eilertson, B., Fulton, S. A., Flynn, J. L., and Canaday, D. H. (2005). The purinergic P2X7 receptor is not required for control of pulmonary Mycobacterium tuberculosis infection. Infect. Immun. 73, 3192-3195. doi: 10.1128/IAI.73.5.3192-3195.2005

Pelegrin, P., and Surprenant, A. (2009). The P2X(7) receptor-pannexin connection to dye uptake and IL-1beta release. Purinergic Signal. 5, 129-137. doi: 10.1007/s11302-009-9141-7

Petit-Jentreau, L., Jouvion, G., Charles, P., Majlessi, L., Gicquel, B., and Tailleux, L. (2015). Ecto-5' -Nucleotidase (CD73) Deficiency in Mycobacterium tuberculosis-infected mice enhances neutrophil recruitment. Infect. Immun. 83, 3666-3674. doi: 10.1128/IAI.00418-15

Placido, R., Auricchio, G., Falzoni, S., Battistini, L., Colizzi, V., Brunetti, E., et al. (2006). P2X $\mathrm{X}^{7}$ purinergic receptors and extracellular ATP mediate apoptosis of human monocytes/macrophages infected with Mycobacterium tuberculosis reducing the intracellular bacterial viability. Cell. Immunol. 244, 10-18. doi: 10.1016/j.cellimm.2007.02.001

Ralevic, V., and Burnstock, G. (1998). Receptors for purines and pyrimidines. Pharmacol. Rev. 50, 413-492.

Reutershan, J., Vollmer, I., Stark, S., Wagner, R., Ngamsri, K. C., and Eltzschig, H. K. (2009). Adenosine and inflammation: CD39 and CD73 are critical mediators in LPS-induced PMN trafficking into the lungs. FASEB J. 23, 473-482. doi: 10.1096/fj.08-119701

Sambasivan, V., Murthy, K. J. R., Reddy, R., Vijayalakshimi, V., and Hasan, Q. (2010). P2X7 gene polymorphisms and risk assessment for pulmonary tuberculosis in Asian Indians. Dis. Markers 28, 43-48. doi: 10.1155/2010/843729

Santos, A. A., Rodrigues, V. Jr., Zanin, R. F., Borges, T. J., Bonorino, C., Coutinho-Silva, R., et al. (2013). Implication of purinergic P2X7 receptor in $M$. tuberculosis infection and host interaction mechanisms: a mouse model study. Immunobiology 218, 1104-1112. doi: 10.1016/j.imbio.2013.03.003

Shamsi, M., Zolfaghari, M. R., and Farnia, P. (2016). Association of IFN- $\gamma$ and P2X7 receptor gene polymorphisms in susceptibility to Tuberculosis among Iranian patients. Acta Microbiol. Immunol. Hung 63, 93-101. doi: 10.1556/030.63.2016.1.7

Sharma, S., Kumar, V., Khosla, R., Kajal, N., Sarin, B., and Sehajpal, P. (2010). Association of P2X7 receptor +1513 (A->C) polymorphism with tuberculosis in a Punjabi population. Int. J. Tuberc. Lung Dis. 14, 1159-1163. 
Singla, N., Gupta, D., Joshi, A., Batra, N., and Singh, J. (2012). Genetic polymorphisms in the P2X7 gene and its association with susceptibility to tuberculosis. Int. J. Tuberc. Lung Dis. 16, 224-229. doi: 10.5588/ijtld.1 1.0076

Sluyter, R., and Stokes, L. (2011). Significance of P2X7 receptor variants to human health and disease. Recent Pat. DNA Gene Seq. 5, 41-54. doi: $10.2174 / 187221511794839219$

Soares-Bezerra, R. J., Pinho, R. T., Bisaggio, R. D. C., Benévolo-de-Andrade, T. C., and Alves, L. A. (2015). The search for new agonists to P2X7R for clinical use: tuberculosis as a possible target. Cell. Physiol. Biochem. 37, 409-418. doi: 10.1159/000430364

Tonin, A. A., Da Silva, A. S., Ruchel, J. B., Rezer, J. F., Camillo, G., Faccio, L., et al. (2013). E-NTPDase and E-ADA activities in lymphocytes associated with the immune response of rats experimentally infected with Toxoplasma gondii. Exp. Parasitol. 135, 325-330. doi: 10.1016/j.exppara.2013.07.014

Tonin, A. A., Da Silva, A. S., Casali, E. A., Silveira, S. S., Moritz, C. E., Camillo, G., et al. (2014). Influence of infection by Toxoplasma gondii on purine levels and E-ADA activity in the brain of mice experimentally infected mice. Exp. Parasitol. 142, 51-58. doi: 10.1016/j.exppara.2014.04.008
Velasquez, S., and Eugenin, E. A. (2014). Role of Pannexin-1 hemichannels and purinergic receptors in the pathogenesis of human diseases. Front Physiol. 5:96. doi: 10.3389/fphys.2014.00096

Wu, J., Lu, L., Zhang, L., Ding, Y., Wu, F., Zuo, W., et al. (2015) Single nucleotide polymorphisms in P2X7 gene are associated with serum immunoglobulin G responses to Mycobacterium tuberculosis in tuberculosis patients. Dis. Markers 2015, 671272-671277. doi: 10.1155/2015/ 671272

Conflict of Interest Statement: The authors declare that the research was conducted in the absence of any commercial or financial relationships that could be construed as a potential conflict of interest.

Copyright (c) 2017 Petit-Jentreau, Tailleux and Coombes. This is an open-access article distributed under the terms of the Creative Commons Attribution License (CC $B Y)$. The use, distribution or reproduction in other forums is permitted, provided the original author(s) or licensor are credited and that the original publication in this journal is cited, in accordance with accepted academic practice. No use, distribution or reproduction is permitted which does not comply with these terms. 